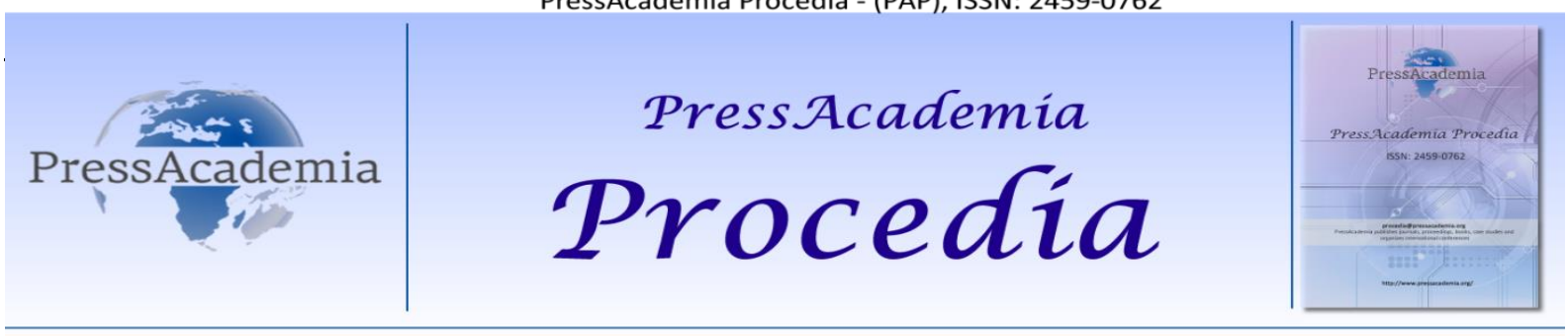

Istanbul Finance Congress (IFC), November 2-3, 2017, Istanbul, Turkey

\title{
FUZZY REAL OPTION VALUATION MODEL USING TRINOMIAL LATTICE APPROACH AND ITS PROPERTY CONSTRUCTION INVESTMENT APPLICATION
}

\author{
DOI: 10.17261/Pressacademia.2017.739 \\ PAP-IFC- V.6-2017(3)-p.19-23
}

\author{
Huseyin Yigit Ersen ${ }^{1}$, Oktay Tas $^{2}$ \\ ${ }^{1}$ Istanbul Technical University, Faculty of Management, Istanbul, Turkey. ersenh@itu.edu.tr \\ ${ }^{2}$ Istanbul Technical University, Faculty of Management, Istanbul, Turkey. oktay.tas@itu.edu.tr
}

\section{To cite this document}

Ersen, H.Y., Tas, O. (2017). Fuzzy real option pricing model using trinomial lattice approach and its property construction investment application. PressAcademia Procedia (PAP), V.6., p.19-23.

Permanant link to this document: $\underline{\text { http://doi.org/10.17261/Pressacademia.2017.739 }}$

Copyright: Published by PressAcademia and limited licenced re-use rights only.

\begin{abstract}
Objective- Decision makers usually use conventional methods in appraising investment projects. However, nowadays, dynamic valuation models about the future of investments also needs to be included in the decision making process. This study aims to show that a property construction investment project, which seems to be unprofitable with conventional methods currently, can be implemented profitably in the future by using a fuzzy real option method with dynamic characteristics. Using fuzzy numbers in addition to the classical fuzzy option theory will expand the model's scope and enable it to contain more information, thereby making it more appropriate for investment environments with high uncertainty. In addition, both the standard deviation calculated from expected value of the fuzzy numbers and the historical volatility will be used for the fuzzy real option valuation. Thus, it is aimed to compare the two methods. Finally, it is aimed to transfer expert opinions to the model as well.

Methodology- The project valuation of a property construction investment planned to be made in Turkey has been performed by using Trinomial Fuzzy Real Option method. First, the volatility variable of this model was determined on the basis of Carlsson and Fuller's proposal of expected values and standard deviations for fuzzy numbers. Next, the historical volatility of house price index used for the volatility variable of the model. Finally, these two methods were compared. The model also includes expert opinions. These expert opinions have been transferred to the model with the aggregation of fuzzy numbers.

Findings- According to the valuation conducted with Trinomial Fuzzy Real Options, the property construction investment project, which seems to be unprofitable currently, can be implemented profitably in the future. Due to the transactional nature of fuzzy numbers, volatility value, which is calculated on the basis of standard deviation of cash flows, will increase per annum. On the other hand, the historical volatility is used as a constant for all investment years. In parallel with this approach, the optimum investment year of the model using the standard deviation of cash flows as volatility has been different the model with historical volatility.

Conclusion- The idea of using options in investment projects adds both managerial flexibility and uncertainty concepts to the valuation process. In addition to the term volatility, which is used for the concept of uncertainty in the model, the naturally existent uncertainty of fuzzy numbers is also used in the model. Furthermore, it is shown that the investment project, which seems to be unprofitable currently, can be carried out profitably in the future with the managerial flexibility of a delay option. While the volatility, which is calculated on the basis of the standard deviation of cash flows, postpones the optimum investment timing with its increasing value, the historical volatility model gives earlier optimum investment timing.
\end{abstract}

Keywords: Real options, property investment, fuzzy sets, net present value, investment projects, trinomial fuzzy real option valuation. JEL Codes: G13, G31, L74 


\section{TRINOMIAL KAFES YAKLAŞIMI KULLANARAK BULANIK REEL OPSIYON DEĞERLEMESI VE GAYRIMENKUL YATIRIMI UYGULAMASI}

\section{ÖZET}

Amaç- Yatııım projeleri karar vericiler tarafından değerlenirken genellikle statik olan klasik yöntemler kullanılır. Ancak günümüzde yatıımın geleceği ile ilgili dinamik değerleme modellerinin de karar verme süreçlerinde yer alması gerekmektedir. Bu çalışmada klasik yöntemlerle bugün için yapılması karlı gözükmeyen bir gayrimenkul yatıım projesinin dinamik bir yapıya sahip olan bulanık reel opsiyon yöntemi ile gelecekte karlı bir şekilde yapılabileceğinin gösterilmesi amaçlanmıştır. Klasik bulanık opsiyon teorisine ek olarak modelde bulanık sayıların da kullanılması modelin kapsamını artıracak ve daha fazla bilgi içermesini sağlayacaktır. Böylelikle model yoğun bilinmezliğin olduğu yatııı ortamlarına daha uygun hale gelecektir. Ayrıca bulanık reel opsiyon değerlemesinde hem bulanık sayıların beklenen değeri üzerinden hesaplanan standart sapma ve hem de tarihsel oynaklık kullanılacaktır. Böylelikle iki yöntemin karşılaştırılması amaçlanmıştır. Son olarak uzman görüşlerinin modele aktarılması da amaçlanmıştır.

Yöntem- Türkiye'de yapılması planlanan bir gayrimenkul yatırım projesinin değerlemesi Trinomial Bulanık Reel Opsiyon yöntemi ile yapılmıştır. Bu modelin içerdiği oynaklık değişkeni ilk olarak Carlsson ve Fuller'in bulanık sayıların beklenen değeri ve standart sapması önerisi ile yapılmıştır. İinci olarak ise modeldeki oynaklık değişkeni için konut fiyat endeksinin tarihsel oynaklığı kullanılmıştır. Daha sonra bu iki yöntem karşılaştııılmıştır. Modelde ayrıca uzman görüşleri de yer almıştır. Bu uzman görüşleri bulanık sayıların bütünleştirilmesi ile modele aktarılmıştır.

Bulgular- Trinomial Bulanık Reel Opsiyon yöntemi ile yapılan değerlemede günümüz için karlı gözükmeyen gayrimenkul yatırım projesi gelecekte karlı bir şekilde yapılabilecektir. Bulanık sayıların işlem doğası gereği nakit akışlarının standart sapması üzerinde hesaplanan oynaklık değeri her sene artacaktır. Tarihsel oynaklık ise bütün yatırım yılları için sabit olarak kullanılacaktır. Bu yaklaşıma paralel olarak nakit akışlarının standart sapmasını oynaklık olarak kullanan modelin en uygun yatıım yılı tarihsel oynaklık kullanılan modelden farklı olarak bulunmuştur.

Sonuç- Yatırım projelerinde opsiyonların kullanılması fikri değerleme sürecine hem yönetimsel esneklik hem de belirsizlik kavramlarını katmaktadır. Modelde belirsizlik kavramı için kullanılan oynaklık ifadesine ek olarak bulanık sayıların doğası gereği sahip olduğu belirsizlik de kullanılmıştır. Ayrıca günümüz için karlı gözükmeyen yatııım projesinin yönetimsel bir esneklik olan erteleme seçeneği ile gelecekte karlı bir şekilde yapılabileceği gösterilmiştir. Nakit akışlarının standart sapmasından hesaplanan volatilite artan değeri ile projenin optimum yatıım zamanını ertelerken, tarihsel volatiliteli model daha erken optimum yatırım zamanı sonucunu vermiş̧tir.

Anahtar Kelimeler: Reel opsiyonlar, gayrimenkul yatııımı, bulanık kümeler, net bugünkü değer, yatırım projeleri, trinomial bulanık reel opsiyon değerlemesi.

JEL Kodları: G13, G31, L74

\section{Gíriş}

Günümüzde karar vericiler ve yöneticiler yatırım projelerini değerlerken klasik olan durağan yöntemleri kullanmaktadırlar. Net bugünkü değer, iç verim oranı, geri ödeme süresi, ortalama karlılık oranı gibi klasik yöntemler projelerin içinde bulunduğu durumda belirsizlik etkisini değerleme sürecine yansıtamamaktadırlar. Ayrıca bu gibi değerleme yöntemleri projeyi erteleme, iptal etme veya yatırımı gelecekte genişletme gibi yönetimsel esneklikleri içermemektedirler. Bu noktada finansal opsiyonlardan türemiş reel opsiyon değerleme yöntemi karar vericilere ve yöneticilere belirsizlik ve yönetimsel esnekliği içeren dinamik bir değerleme süreci imkanı tanımaktadır. Dahası bulanık sayılarla modellenen reel opsiyonlar bulanık sayıların doğası gereği daha fazla bilgi içeren değerleme modeli olacaktır. Bilinmezliğin yoğun olduğu yatırım ortamlarında bilgi kapsamını genişleterek daha doğru bir değerleme imkanı sunacaktır.

Bu çalışmada klasik yöntemlerle şu an için karlı gözükmeyen Trakya Bölgesi'nde yer alan bir arsa üzerine inşaat yatıımı projesinin ertelenerek gelecekte karlı bir şekilde yapılabileceği gösterilecektir. Bu yatırım projesinin geniş bilinmezlik ortamında gerçeklenecek olması nedeniyle bu değerleme süreci bulanık sayılarla trinomial reel opsiyon değerlemesi ile yapılacaktır. Dahası model içindeki belirsizlik ifadesi olan oynaklık değişkeni için bulanık sayılarda standart sapma hesabı ile değerlenen model ve tarihsel volatilite ile değerlenen modeller karşılaştırılacaktır. Süreç içerisinde uzman görüşleri kullanılacaktır. Bazı değişimler için ise uzman görüşlerinin bütünleştirilmesi kullanılacaktır.

\section{LITERATÜR INCELEMESi}

Literatürde bulanık reel opsiyonlar bir çok çalışmada kullanılmışıı. Ilk olarak Carlsson ve Fuller (2003) tarafından nakit akışları ve maliyetlerin klasik sayı olarak ifade edilemeyeceği durumlar için Black \& Scholes (1973) modelini baz alan bulanık opsiyon değerleme modeli oluşturulmuştur. Bu modelde nakit akışları ve maliyetleri bulanık sayı olarak ifade etmişlerdir.

Uçal ve Kahraman (2009) petrol yatırımı uygulamasında bulanık opsiyon değerlemesini kullanmışlardır. Bu çalışmada bilgi kaybını en aza indirmek için bulanık nakit akışı ve maliyetlerin beklenen değeri sonradan alınmıştır. Tolga, Kahraman, Demircan (2009) çağrı merkezi yatııımı değerlemesini bulanık reel opsiyonlarla yapmıştır. Çalışmada bulanık sayıların reel opsiyon trinomial kafes uygulaması ve Black \& Scholes uygulaması karşılaştıııımışır. You ve diğerleri (2012) bulanık reel opsiyon değerlemesini kurumsal kaynak planlaması yatırımı için kullanmışlardır. Montsho (2012) bulanık reel opsiyon yaklaşımını çalışmakta olan nükleer reaktör yatıııını feshetme seçeneğini için kullanmıştır. Dai, Sun, Guo (2016) Black \& Scholes modeline dayanan bulanık reel opsiyon modeli ile daha önceden kirlilik yayan bir tesisin kirlilik yaymayacak şekilde geliştirilmesi (brownfield redevelopment) projesini değerlemişlerdir. Ayrıca değerleme uzmanların risk algısını da 
içermektedir. Aranda, Arango ve Lianos (2016) Amerikan alım opsiyonları için bulanık reel opsiyon değerlemesini yardımcı demiryolu nakliyesi terminalinin dağıtım merkezi uygulaması için kullanmışlardır. Biancardi ve Villani (2017) birleşik Amerikan döviz opsiyonlarını bulanık mantık yaklaşımı ile modellemişlerdir.

\section{VERI, YÖNTEM, BULGULAR, ANALIZ}

Zadeh'in (1965) önerdiği bulanık küme teorisi günümüze kadar bir çok çalışmada kullanılmıştır. Bulanık küme teorisinden bir çok bulanık sayı çeşidi literatürde mevcuttur. Bu çalışmada tip-1 trapezoidal bulanık sayılar kullanılacaktır. $\tilde{A}=\left(a_{1}, a_{2}, a_{3}, a_{4}\right)$ olmak üzere bulanık bir sayı aşağıdaki gibi ifade edilebilir:

Şekil 1: Trapezoidal Bulanık Sayı

$\mu_{A}(x)=\left\{\begin{array}{cl}\frac{\left(x-a_{1}\right)}{\left(a_{2}-a_{1}\right)}, & a_{1} \leq x<a_{2} \\ 1, & a_{2} \leq x<a_{3} \\ \frac{\left(a_{4}-x\right)}{\left(a_{4}-a_{3}\right)}, & a_{3} \leq x<a_{4} \\ 0, & \text { diğer }\end{array}\right.$

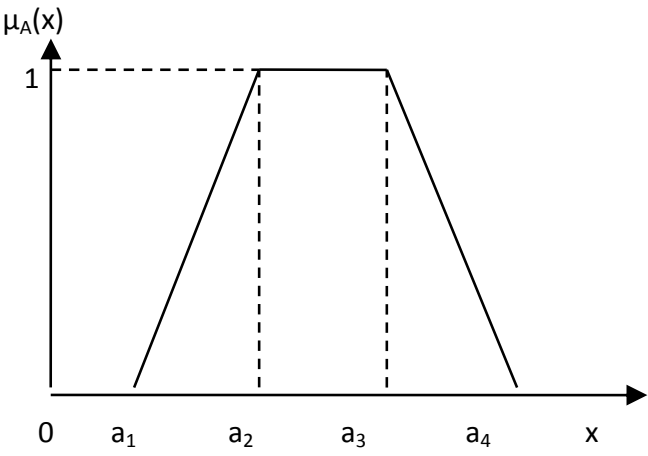


Başlangıç yılı nakit akışları, " $\tilde{X}$ " İlk yatırım maliyeti, " $\Delta t$ " Yatırım her bir basamak zaman aralığı ( yıl bazlı kullanılmıştır), " $r$ " Risksiz faiz oranı, " $u$ " Bir sonraki döneme geçişte nakit akışlarının artma oranı, " $d$ " Bir sonraki döneme geçişte nakit akışlarının azalma oranı, " $p_{u}$ " Bir sonraki döneme geçişte u değişikliği olma olasılığı, " $p_{m}$ " Bir sonraki döneme geçişte sabit kalma olasılığı, " $p_{d}$ " Bir sonraki döneme geçişte d değişikliği olma olasılığı, " $\sigma$ " Oynaklık değişkeni ( 1- Posibilistik standart sapma, 2- Tarihsel Oynaklık), " $\delta$ " Yatırım kararı süreci boyunca opsiyonun değer kaybı- Finansal opsiyonlarda temettülü modelleme.

Bulanık reel opsiyon trinomial değerleme şeması Şekil 2'de gösterilmiştir:

Şekil 2: Trinomial Yaklaşımla Bulanık Reel Opsiyon Değerleme Şeması

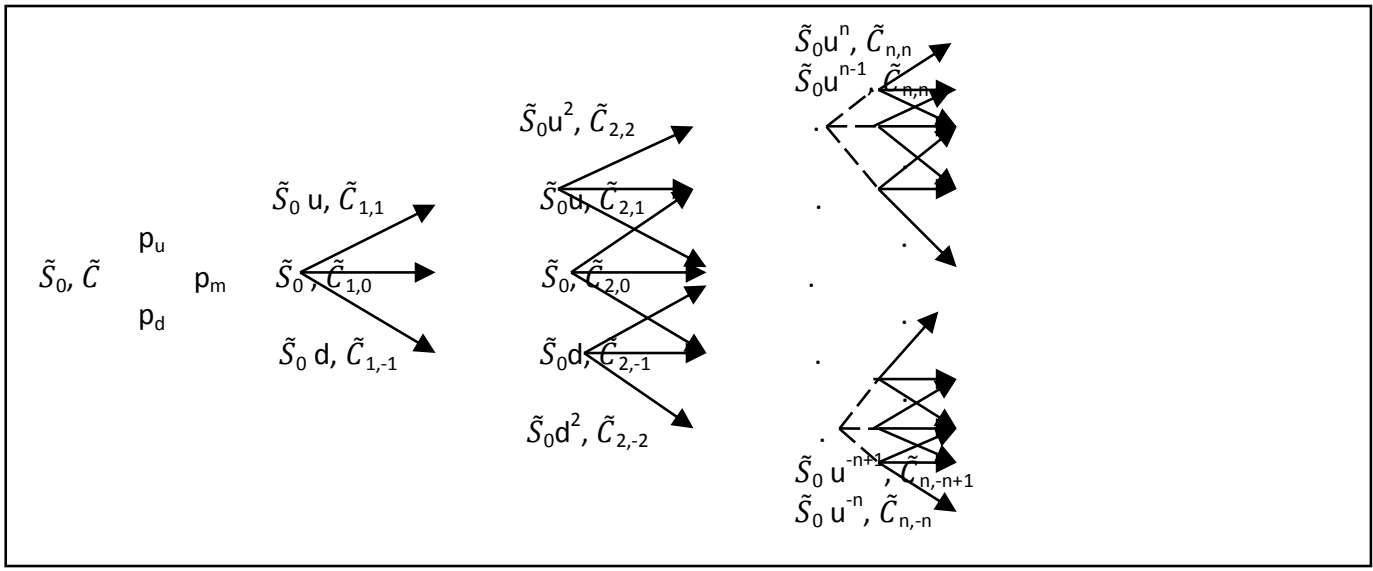

Modelin formülasyonu ise şu şekildedir:

$v=r-\delta-\frac{1}{2} \sigma^{2}, \Delta x=\sigma \sqrt{3 \Delta t}, u=e^{\Delta x}, d=1 / u$,

$\mathrm{p}_{\mathrm{u}}=(1 / 2)\left(\left(\left(\sigma^{2} \Delta \mathrm{t}+\mathrm{v}^{2} \Delta \mathrm{t}^{2}\right) / \Delta \mathrm{x}^{2}\right)+(v \Delta \mathrm{t} / \Delta \mathrm{x})\right), \mathrm{p}_{\mathrm{m}}=1-\left(\left(\sigma^{2} \Delta \mathrm{t}+\mathrm{v}^{2} \Delta \mathrm{t}^{2}\right) / \Delta \mathrm{x}^{2}\right), \mathrm{p}_{\mathrm{d}}=(1 / 2)\left(\left(\left(\sigma^{2} \Delta \mathrm{t}+\mathrm{v}^{2} \Delta \mathrm{t}^{2}\right) / \Delta \mathrm{x}^{2}\right)-(v \Delta \mathrm{t} / \Delta \mathrm{x})\right)$

$\tilde{S}_{i, j}=\tilde{S}_{0}(1-\delta) u^{j} \quad, j=-i, \ldots ., 0, \ldots, i, \tilde{C}_{T, j}=\operatorname{maks}\left(0, \tilde{S}_{T, j}-\widetilde{X}\right), j=-T, \ldots ., 0, \ldots ., T, \tilde{C}_{i, j}=e^{-r \Delta t}\left(p_{u} \tilde{C}_{i+1, j+1}+p_{m} \tilde{C}_{i+1, j}+p_{d} \tilde{C}_{i+1, j-1}\right)$

Modelde kullanılan beklenilen değer, standart sapma ve oynaklık ifadeleri Carlsson ve Fuller'e (2001) göre bulunur:

$E(\tilde{A})=\left(a_{1}+2 a_{2}+2 a_{3}+a_{4}\right) / 6$ 
$\sigma^{2}(\tilde{\mathrm{A}})=\left(\mathrm{a}_{3}-\mathrm{a}_{2}\right)^{2} / 4+\left(\left(\mathrm{a}_{3}-\mathrm{a}_{2}\right)\left(\mathrm{a}_{4}-\mathrm{a}_{1}\right)\right) / 6+\left(\mathrm{a}_{4}-\mathrm{a}_{1}\right)^{2} / 24$, Standartlaştırma işlemi: $\sigma^{*}=\sigma / \mathrm{E}(\tilde{\mathrm{A}})$

" $n+1$ " Gözlem sayısı, " $S_{j}$ ” j. dönem sonunda dayanak varlık fiyatı, " $T$ ” Yıl bazında zaman aralığı olmak üzere tarihsel oynaklık hesaplama adımları ise şu şekildedir:

$\mathrm{u}_{\mathrm{j}}=\ln \left(\mathrm{S}_{\mathrm{j}} / \mathrm{S}_{\mathrm{j}-1}\right)$, " $\mathrm{u}_{\mathrm{j}}$ " değişkeninin standart sapması " $\mathrm{s}$ " ile ifade edilir:

$s=v\left[(1 / n-1) \Sigma\left(u_{j}-\bar{u}\right)^{2}\right] \quad j=1,2, \ldots, n$.

" $\bar{u}$ ", " $u_{j}$ ” verilerinin aritmetik ortalamasıdır. Volatilite (oynaklık) ise $\sigma=s / v T$ şeklinde elde edilir.

Trigeorgis (1993)'e göre bir projenin karlılığı aşağıdaki şekilde değerlendirilebilir:

Genişletilmiş NBD = Geleneksel NBD + Opsiyon Primi

Gayrimenkul yatırımı uygulaması:

$1.400 \mathrm{~m}^{\wedge} 2$ arazi - \%25 imarlı -2 katlı $-700 \mathrm{~m}^{\wedge} 2$ inşaat alanlı oturma alanı projesi-10 daire, arsa maliyeti $1.000 .000 \mathrm{TL}$, ilk yıl 4 (225.000 TL), ikinci yıl 4 (1.000.000 TL), üçüncü yıl (550.000 TL) satış gelirleri, ilk yatırımın yarısı 3 sene geri ödemeli banka kredisi, 7 senelik yatırım hakkı boyunca her yıl için, $\delta=0.05, r=0.115, A O S M=\% 20$. Maliyetlerin yıllara göre aldığı aşağıdaki tabloda gösterilmiştir(gelecekteki maliyetler uzman görüşlerinin bulanık sayı ifadesi ile oluşturulmuştur) :

Tablo 1: Yıllara Göre Maliyetler

\begin{tabular}{|l|l|l|l|}
\hline YIL & INŞAAT MALIYETi & ARSA MALIYETi & TOPLAM \\
\hline 0 & 794255 & 1000000 & 1794255 \\
\hline 1 & $(850074,867295,884515,901736)$ & $(1059874,1079877,1099879,1119881)$ & $(1909948,1947171,1984394,2021616)$ \\
\hline 2 & $(910260,947393,985318,1024035)$ & $(1123333,1166133,1209733,1254133)$ & $(2033593,2113527,2195052,2278169)$ \\
\hline 3 & $(975179,1035263,1097929,1163234)$ & $(1190592,1259280,1330560,1404480)$ & $(2165771,2294543,2428489,2567714)$ \\
\hline 4 & $(1045232,1131690,1223766,1321710)$ & $(1297600,1397650,1503376,1614989)$ & $(2342832,2529340,2727141,2936699)$ \\
\hline 5 & $(1120852,1237543,1364421,1502179)$ & $(1414225,1551223,1698637,1857050)$ & $(2535077,2788766,3063058,3359230)$ \\
\hline 6 & $(1202513,1353780,1521685,1707748)$ & $(1541332,1721671,1919260,2135392)$ & $(2743845,3075451,3440944,3843140)$ \\
\hline 7 & $(1290729,1481462,1697567,1942968)$ & $(1679863,1910848,2168537,2455454)$ & $(2970593,3392310,3866104,4397422)$ \\
\hline
\end{tabular}

Satış fiyatlarındaki uzman görüşlerine dayanan bulanık sayı değişim aşağıdaki tabloda gösterilmiştir:

Tablo 2: Uzman Görüşlerine Göre Satış Fiyatı Değişimi

\begin{tabular}{|l|l|l|l|l|l|}
\hline Satış ilk 2 yıl & Değişim (yıllık) & Satış 3-4 yıl & Değişim (yıllık) & Satış 5-7 yıl & Değişim (yıllık) \\
\hline KV1 & $(1.10,1.133,1.666,1.20)$ & KV1 & $(1.10,1.12,1.4,1.16)$ & KV1 & $(1.06,1.08,1.10,1.12)$ \\
\hline KV2 & $(1.08,1.113,1.466,1.18)$ & KV2 & $(1.09,1.11,1.13,1.15)$ & KV2 & $(1.07,1.09,1.11,1.13)$ \\
\hline KV3 & $(1.12,1.533,1.866,1.22)$ & KV3 & $(1.08,1.10,1.12,1.14)$ & KV3 & $(1.05,1.06,1.07,1.08)$ \\
\hline Geometrik B. & $(1.10,1.133,1.666,1.20)$ & Geometrik B. & $(1.09,1.11,1.13,1.15)$ & Geometrik B. & $(1.060,1.077,1.093,1.11)$ \\
\hline
\end{tabular}

Tarihsel oynaklık: TR21 kodlu konut fiyat endeksi Temmuz 2010'dan Temmuz 2017'ye 8 adet veri = 0,049 ( her yıl için aynı). Posibilistik standart sapmadan hesaplanan oynaklık: $0.086,0.162,0.213,0.266,0.326,0.390,0.428$ (sırasıyla her bir yıl için).

Bugün için yapılan değerleme sonucunda NBD -1.752 TL çıkmıştır. NBD analizine göre proje küçük de olsa bir farkla yapılamaz durmaktadır. 7 farklı yılın her biri için değerleme yapılmasına karar verilmiştir. Genişletilmiş NBD’ye göre optimum yatırım yılının bulunması için 2 farklı oynaklık tipine göre analiz yapılmıştır. Aşağıdaki bu analizlerin sonuçları tabloda gösterilmiştir:

Tablo 3: Posibilistik Oynaklık Kullanılan Modelde* ve Tarihsel Volatiliteli Modelde' Yapılan Değerlemeler

\begin{tabular}{|c|c|c|c|c|c|c|}
\hline $\begin{array}{c}\text { Yatırım } \\
\text { Yılı }\end{array}$ & $\begin{array}{c}\text { Bulanık } \\
\text { Genişletilmiş NBD* }\end{array}$ & $\begin{array}{c}\text { Beklenen Gen. } \\
\text { NBD* }\end{array}$ & $\begin{array}{c}\text { Beklenen Ops. } \\
\text { Değeri* }\end{array}$ & $\begin{array}{c}\text { Bulanık Gen. } \\
\text { NBD' }\end{array}$ & $\begin{array}{c}\text { Beklenen Gen. } \\
\text { NBD' }\end{array}$ & $\begin{array}{c}\text { Beklenen Ops. } \\
\text { Değeri' }\end{array}$ \\
\hline 1 & $\begin{array}{c}(-34924,34340, \\
125198,230464)\end{array}$ & 85769,164 & 16776,37 & $\begin{array}{c}(-34924,34340, \\
105478,229975)\end{array}$ & 79114,28 & 10121,48 \\
\hline 2 & $\begin{array}{c}(-61522,80038, \\
262663,485791)\end{array}$ & 184945,07 & 53899,32 & $\begin{array}{c}(-63471,65382, \\
218030,453947)\end{array}$ & 159549,78 & 28504,04 \\
\hline 3 & $\begin{array}{c}(-95300,92471, \\
316724,568333)\end{array}$ & 215237,44 & 65947,63 & $\begin{array}{l}(-98572,65348, \\
241663,531581)\end{array}$ & 174505,35 & 25215,54 \\
\hline 4 & $\begin{array}{l}(-140910,81926, \\
337827,636985)\end{array}$ & 222596,90 & 76566,74 & $\begin{array}{l}(-147491,46409, \\
243274,555733)\end{array}$ & 164601,21 & 18641,65 \\
\hline
\end{tabular}




\begin{tabular}{|c|c|c|c|c|c|c|}
\hline 5 & $\begin{array}{c}(-208660,33736, \\
302729,629485)\end{array}$ & 182292,45 & 76341,19 & $\begin{array}{c}(-216093,-3063, \\
212549,497844)\end{array}$ & 116787,01 & 10967,61 \\
\hline 6 & $\begin{array}{c}(-262963,-6029, \\
286978,623543)\end{array}$ & 153246,53 & $\mathbf{8 1 9 6 1 , 9 6}$ & $\begin{array}{c}(-272888,-44774, \\
185119,450509)\end{array}$ & 76385,29 & 5285,41 \\
\hline 7 & $\begin{array}{c}(-286070,-22381, \\
276805,605203)\end{array}$ & 137996,52 & 73245,10 & $\begin{array}{c}(-291335,-54943, \\
182406,424020)\end{array}$ & 64601,77 & 73,42 \\
\hline
\end{tabular}

Bulanık sayının standart sapmasından elde edilen oynaklığın kullanıldığı modelde Genişletilmiş NBD kriterine göre proje 4. yılda gerçeklenmelidir. Bu proje kararındaki ana kriterimizdir.Proje en yüksek opsiyon değerine ise 6. yılda yapılacak yatırımla ulaşmaktadır. Tarihsel oynaklığın kullanıldığı modelde proje ana kriterimiz olan Genişletilmiş NBD'ye göre 3. yılda gerçeklenmelidir. Bu modelde ayrıca opsiyon değeri 2. yılda gerçeklenen proje ile maksimuma ulaşmaktadır.

\section{SONUÇ, TARTIŞMA}

Reel opsiyon teorisinin yatırım projelerinde kullanılması karar sürecine yönetimsel esneklik ve belirsizlik kavramlarını katmaktadır. Reel opsiyonların bulanık sayılar ile kullanılması belirsizlik değişkeni olarak kullanılan oynaklık ifadesine ek olarak bulanık sayıların doğası gereği sahip olduğu belirsizliği de modele eklemiştir. Diğer taraftan günümüz için karlı gözükmeyen yatırım projesinin reel opsiyonların sahip olduğu erteleme yönetimsel esnekliği ile gelecekte karlı olarak yapılabileceği gösterilmiştir. Dahası optimum yatırım yılı da belirlenmiştir. Tarihsel volatiliteli model daha kısa erteleme sonucunu verirken, nakit akışlarının standart sapmasından hesaplanan volatiliteli modelin artan volatilitesiyle daha geç reelize etme sonucunu vermiştir. Gelecek çalışmalarda bu model belirsizliğin olduğu diğer çalışmalarda kullanılabilir. Ayrıca çoklu karar verme süreçleri, istatistiksel yöntemlerle birlikte kullanılabilir, diğer bulanık sayı kümeleriyle modellenebilir.

\section{KAYNAKLAR}

Aranda, F., C., Arango, F., O., Lianos, A., I., C., 2016, Project Valuation of a Distribution Centre of an Auxiliary Rail Freight Terminal: Using Real Options with Fuzzy Logic and Binomial Trees, Journal of Applied Economic Sciences,11, 894-904.

Biancardi, M., Villani, G., 2017, A fuzzy approach for R\&D compound option valuation, Fuzzy Sets and Systems, 310, 108-121.

Black, F., Scholes, M., 1973, The pricing of options and corporate liabilities, Journal of Political Economy, 81, 637-654.

Carlsson, C., Fuller, R., 2001, On possibilistic mean value and variance of fuzzy numbers, Fuzzy Sets and Systems, 122, 315-326.

Carlsson, C., Fuller, R., 2003. A fuzzy approach to real option valuation. Fuzzy Sets and Systems, 139, 297-312.

Clewlow, L., Strickland, C., 1998, Implementing derivatives models. Chichester: John Wiley \& sons, Inc.

Cox, J. C., Ross, S. A. Rubinstein, M., 1979, Option pricing: a simplified approach. Journal of Financial Economics, 7, 229-263.

Dai, H., Sun, T., Guo, W., 2016, Brownfield Redevelopment Evaluation Based on Fuzzy Real Options, Sustainability, 8, 170.

Montsho, O., 2012, Real Options Valuation for South African Nuclear Waste Management Using a Fuzzy Mathematical Approach, Msc. Thesis, Rhodes University Department of Mathematics.

Tolga, A. C., Kahraman, C., Demircan, M. L., 2009, A Comparative Fuzzy Real Options Valuation Model using Trinomial Lattice and BlackScholes Approaches: A Call Center Application, Journal of Multiple Valued Logic \& Soft Computing, 16, 135-154.

Trigeorgis, L., 1993, Real options and interactions with financial flexibility. Financial Management, 22, 202-224.

Ucal, I., Kahraman, C., 2009, Fuzzy real options valuation for oil investments, Technological and Economic Development of Economy, 15, 4, 646-669.

You, C. J., Lee, C. K. M., Chen, S. L., Jiao, R. J., 2012, A real option theoretic fuzzy evaluation model for enterprise resource planning investment, Journal of Engineering and Technology Management, 29(1), 47-61.

Zadeh, L. A., 1965, Fuzzy sets. Information and Control, 8, 338-353. 